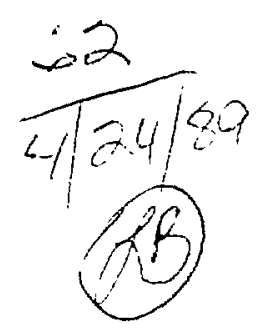

Chemistry Division Chemistry Division Chemistry Division (1) ANL-89/9 ANL- $-89 / 9$ DE89 010277

Chemistry Division

Chemistry Division Chemistry Division

\title{
Isotopic Anomalies in High Z Elements: Uranium?
}

\author{
by S. Jovanovic, G. W. Reed, Jr., \\ A. M. Essling, E. G. Rauh, \\ and D. G. Graczyk
}

Argonne National Laboratory, Argonne, Illinois 60439 operated by The University of Chicago

for the United States Department of Energy under Contract W-31-109-Eng-38 
A major purpose of the Technical Information Center is to provide the broadest dissemination possible of information contained in DOE's Research and Development Reports to business, industry, the academic community, and federal, state and local governments.

\section{Although a small portion of this} report is not reproducible, it is being made available to expedite the availability of information on the research discussed herein. 
Argonne National Laboratory, with facilities in the states of Illinois and Idaho, is owned by the United States govemment. and operated by The University of Chicago under the provisions of a contract with the Department of Energy.

\section{DISCLAIMER}

This report was prepared as an account of work sponsored by an agency of the United States Government. Neither the United States Government nor any agency thereof. nor any of their employees, makes any warranty. express or implied, or assumes any legal liability or responsibility for the accuracy, completeness, or usefulness of any information, apparatus. product, or process disclosed. or represents that its use would not infringe privately owned rights. Reference herein to any specific commercial product. process, or service by trade name, trademark, manufacturer, or otherwise, does not necessarily zonstitute or imply its endorsement, recommendation, or favoring by the United States Government or any agency thereof. The views and opinions of authors expressed herein do not necessarily state or reflect those of the United States Government or any agency thereof.

This report has been reproduced from the best available copy.

Available from the

National Technical Information Service

NTIS Energy Distribution Center

P.O. Box 1300

Oak Ridge. TN 37831

Price: Printed Copy A03

Microfiche A01 


$$
\text { ANL }-89 / 9
$$

\section{ARGONNE NATIONAL LABORATORY \\ 9700 South Cass Avenue \\ Argonne, Illinois 60439}

ISOTOPIC ANOMALIES IN HIGH $Z$ ELEMENTS: URANIUM?

$$
\text { by }
$$

S. Jovanovic and G. W. Reed, Jr.

Chemistry Division

$$
\text { and }
$$

A. M. Essling, E. G. Rauh, and D. G. Graczyk

$$
\begin{gathered}
\text { Analytical Chemistry Laboratory } \\
\text { Chemical Technology Division }
\end{gathered}
$$

March 1989 


\section{TABLE OF CONTENTS}

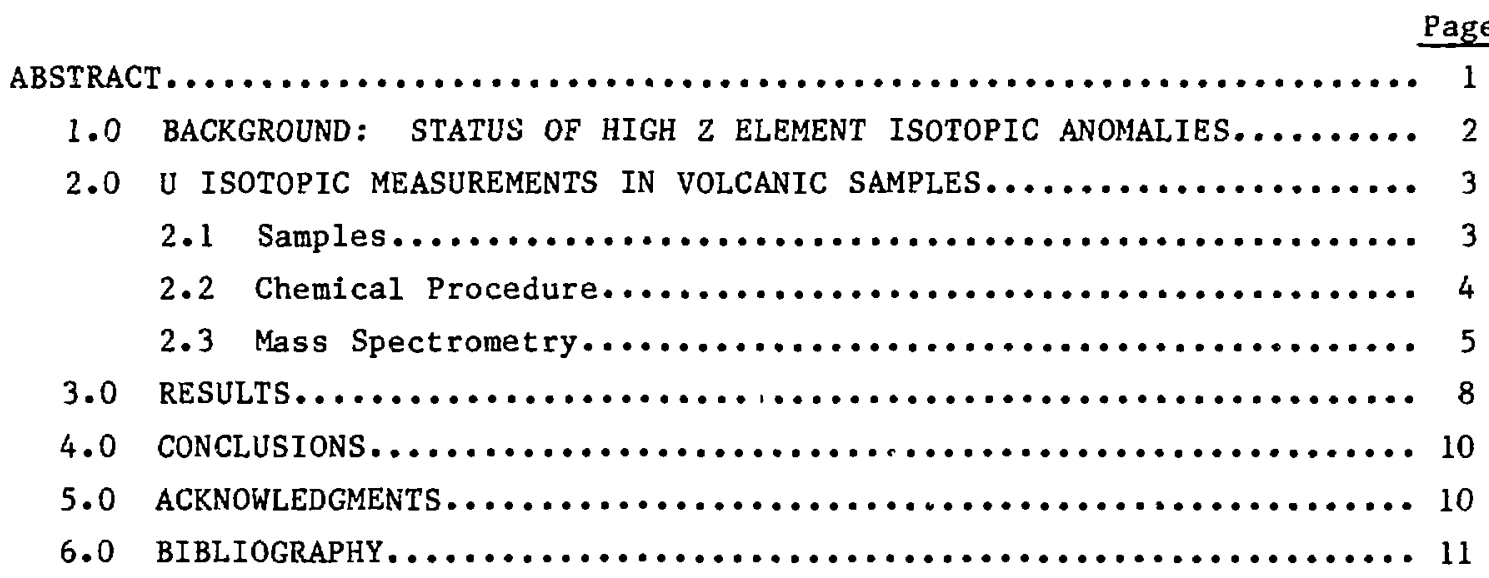


ISOTOPIC ANOMALIES IN HIGH Z ELEMENTS: URANIUM?

S. Jovanovic, G. W. Reed, Jr.

A. M. Essling, E. G. Rauh, and D. G. Graczyk

\section{ABSTRACT}

Uranium in terrestrial volcanic ejecta from mantle-related sources has been analyzed mass spectronetrically. The objective was to seek supporting evidence for or refutation of isotopic variations reported by Fried et al. (1985) for some such samples. The possibility that terrestrial $U$ is not of constant isotopic composition is extraordinary. If true, mechanisms for creating the variation mist be sought and the lack of homogenization within the earth addressed.

Samples of 100 grams or more were processed in order to minimize reagent and environmental (laboratory) blank interference and to permit isolation of large amounts (several to tens of $\mu \mathrm{g}$ ) of $U$ for the mass spectrometer (MS) measurements, which utilize aliquots of $\sim 1 \mathrm{j} g$. Aljquants from four volcanic samples gave data which indicate enrichments of $235 \mathrm{U}$ ranging from $0.2 \%$ to $5.9 \%$ in the $235 / 238$ ratio relative normal uranium ratios. These relative enrichments are consistent with, and in some cases, higher than the $0.18 \%$ enrichment reported by Fried et al. (1935) for two volcanic lava samples. However, we were not able to reproduce their results on the Kilauea lava for which they report $0.18 \% 235_{U}$ enrichment. The relative error in our MS ratios is $0.05 \%-$ $0.07 \%$. A reagent and environmental blank gave $U$ concentrations, based on isotopic dilution, of less than $0.2 \%$ of the amount of $U$ recovered in the parallel sample run. A reagent blank, run in parallel with another sample, was below the detection limits of the fluorescence method used and less than $3 \%$ of the $U$ recovered from the sample. Substantially enriched anomalous $U$ in the reagent blanks would be required to account for the $>0.2 \% 235_{U}$ enrichment in the volcanic samples.

The $235_{\mathrm{U}}$ enrichments were measured in experiments conducted at two different laboratories, Argonne National Laboratory (ANL) and the University of Chicago (UC). The normal $U$ in a kilauea sample extracted at the UC suggests that environmentally derived enriched $U$ was not present, hence it is probable that other samples run at UC were not environmentally contaminated. The procedural blank results and the frequent similar $235 \mathrm{U}$ enrichments $(0.19 \%-0.43 \%)$ for samples prepared at the two laboratories is evidence (but not proof) that isotopically anomalous $U$ is present in some terrestrial volcanic samples. Until observed variations in measured enrichments among different portions of a given sample material are resolved, however, this evidence remains suggestive. Additional measurements are needed to ultimately determine whether uranium isotopic variations occur in the earth's mantle. 


\subsection{BACKGROUND: STATUS OF HIGH Z ELEMENT ISOTOPIC ANOHALIES}

The purpose of this report is to summarize the result of our investigations on the possible presence of isotopically anomalous $\mathrm{U}$ in terrestrial lavas of mantle origins. The presence of isotopically anomalous low and middle $Z$ elements is well established (see review by Begemann, 1980). In all cases the matter in which the anomalies were discovered is extraterrestrial. The anomalies of interest are not necessarily radiogenically produced in-situ either by decay of a parent or by nuclear reactions.

The most significant isotopic variation in high $\mathrm{Z}$ elements is in $\mathrm{Pb}$. The variation is not an anomaly, it is the natural occurrence of primordial $\mathrm{Pb}$ which has not been isotopically altered by the decay of $\mathrm{U}$ and Th, e.g., Reed et al. (1960) and included references. Only ${ }^{204} \mathrm{~Pb}$ is not affected by this decay and hence may be used along with the primordial $\mathrm{Pb}$ to determine the radiogenic $\mathrm{Pb}$ present in solar system material.

Three instances of isotopically anomalous high $\mathrm{Z}$ elements ( $\mathrm{Os}, \mathrm{Hg}$, and $\mathrm{U}$ ) have been reported. None have gained general acceptance. Conflicting results are reported for $\mathrm{Hg} .{ }^{196} \mathrm{Hg}$ and ${ }^{202} \mathrm{Hg}$ have been measured by thermal neutron activation analysis. Anomalous isotope $r z=i o s$ have been reported for some unequilibrated chondrites (Reed and Jovanovic, 1969; Jovanovic and Reed, 1976) and for three Antarctic achondrites (Jovanovic and Reed, 1987, 1988 (submitted)). Chondrites and residues from dilute acid dissolution of iron meteorites were also found to contain isotopically anomalous $196_{\mathrm{Hg}}$ vs $202 \mathrm{Hg}$ by Goel and Thakur (1987). In all cases the anomalous $\mathrm{Hg}$ was in specific temperature fractions isolated in stepwise heating experiments; usually the anomalous $\mathrm{Hg}$ represented only a fraction of the $\mathrm{Hg}$ in the sample. The ${ }^{196} \mathrm{Hg}$ was depleted relative to ${ }^{202} \mathrm{Hg}$ from $\sim 25 \%$ to almost total absence. Lunar breccias 14305 and 14312 were also found to contain a $\mathrm{Hg}$ fraction that was relatively depleted in $196 \mathrm{Hg}$ by $\sim 25 \%$ (Jovanovic and Reed, 1977 a dd 1988 (submitted)).

An early mass spectrometric measurement by C. M. Stevens, ANL (private communication), using the 100-inch mass spectrometer, detected isotopically anomalcus $\mathrm{Hg}$. Three other efforts to detect isotopically anomalous $\mathrm{Hg}$ mass spectrometrically failed (von Helden and Begemann, 1976; Begemann, 1980; Lugmair et al., 1978; and Nier and Schluter, 1987). Since the anoralous fractions contain a few percent of the total $\mathrm{Hg}$ in the sample, usually only $\sim 10^{-9}-10^{-11} \mathrm{~g}$ $\mathrm{Hg} / \mathrm{g}$ is isolated and measured. At this level, there may be serious problems with mass spectrometer systems which have $\mathrm{Cu}$ and Au gaskets, efficient getters of $\mathrm{Hg}$. The system will have been exposed to the bulk of the Hg, which is isotopically normal, released from the sample. A serious memory effect could result. The low $\mathrm{Hg}$ isotope abundance at mass 196 may also present problems, some of which are related to hydrocarbon background interference.

Goel (1987) has reported variable ${ }^{190} 0$ s/ $/ 840$ os ratios (up to $50 \%$ ) in acid residues of iron meteorites. Jovanovic and Reed (1977) presented some 
preliminary idta on these Os isotopes in one of the samples of Afollo 14 breccia 14305 measured for $\mathrm{Hg}$. An $16 \%$ deviation from nornal was found. A very much smaller $1.023 \pm 0.008 \%$ os variation was found in an Allende meteorite sample. In neither case have experiments been carried out to confirm the results. Takahashi et al. (1976) report normal os (an average of $0.2 \pm 0.7 \%$ relative 184 Os depletion) in Lwo Allonde samples.

Aricmalies in the $U$ isotopes in extraterrestrial matter have been reported by Arden (1977), Chen and Tilton (1979), and Tatsumoto and Shimamura (1979, 1980), but these effects were not confirmed by Chen and Wasserburg (1981). Isotopically anomalous $U$ has been reported in two types of terrestrial material. In one case the evidence is irrefutable; the variation in isotopic $U$ being due to the Oklo, Gabon natural reaccor. Uranium ore was analyzed. The other published anomalous U results, which have not yet been confirmed, are those from a sample of a Kilauea lava and a sample from a Katmai eruption (Fried et al., 1985). These authors reported an $\sim 0.18 \%{ }^{23} 5_{\mathrm{U}}$ relative enrichment.

G. Cowan and H. Adler (1976) conducted an extensive survey of the literature on $U$ isotopic ratios in terrestrial $U$ ore samplas. Two modal values of the isotopic ratio exhibited a relative difference of $0.03 \%$. In comparison, the $0.18 \% 235 U$ relative enrichment in two basaltic lavas reported by Fried et al. (1985) is very large. Uranium isotopic ratios have been measured in hydrothermai fluids related to midocean ridge volcanism. The most recent results (Chen, 1987) based on analysis of nanogram amounts of $U$ give $235 / 238_{U}$ ratios equal, within error, to those of average sea water and normal $U$. The range of deviations from normal $(-0.52 \%++0.34 \%)$ in the measurements reflects the measurement uncertainty reported. Deviations of the magnitude reported in ores and in volcanic rock samples (i.e., $0.03 \% \rightarrow 0.18 \%$ ) would not be resolved.

\section{$2.0 \mathrm{U}$ ISOTOPIC MEASUREMENTS IN VOLCANIC SAMPLES}

\subsection{Samples}

The possibility that isotopically anomalous $U$ is present and has persisted in the earth over geologic time raises many questions about the genesis of such $\mathrm{U}$ and its isolation in the earth. Volcanic ejecta have the advantage for study in that they may not have been subjected to mixing with isotopicaliy normal crustal material or to isotopic contamination from nuclear fallout. Samples studied represent many volcanically erupted lavas but of special interest are those derived from undisputed mantle sources. Possibly the best candidates for study are ocean ridge and ocean island tholeiitic basaltic glasses. These are quenched lavas and have the least probability of having been permeated by hydrothermal waters. They may best represent their upper and lower mantle sources. We havé measured $U$ in five types of volcanic ejecta: 
Hat Creek basalt (California) - Early erupted high Al, olivine-rich tholeiite from A. T. Anderson, University of Chicago (Anderson and Gottfried, 1972). No macroscopically visible oxidation or segregation veins.

Auvergne (France) - Olivine basalt volcanic bomb from E. Olsen, Field Museum \#G355. Material analyzed was core left after spalling off exterior "onion skin".

Mt. St. Helens (Oregon) - Volcanic ash from D. Swanson, USGS. Vesicular pumice separated by flotation from "wall rock" material was analyzed.

Mauna Loa spatter - Tholeiltic glass from D. Finnegan, LASL; March 1984 collection.

Kilauea basaltic rock - Sample 2565 from E. Olsen, Field Museum. From the batch of material erupted in 1926 and used by Fried et al. (1985).

Two basaltic glass samples were candidates for measurement. Since quantities were limited we first measured the $U$ contents by neutron activation analysis. Mauna Lo? spatter contains $0.18 \mathrm{jg} \mathrm{U} / \mathrm{g}$. An East Pacific Rise (EPR 4HC) glass supplied by $\mathrm{H}$. Craig contained $0.04 \mathrm{\mu g} \mathrm{U} / \mathrm{g}$ and was not analyzed since a typical processing yield of $20-40 \%$ may not have provided enough $U$ for mass spectrometry.

\subsection{Chemical Procedure}

The analysis for $U$ entails protracted dissolution, evaporation, and ion exchange steps. The dissolution of the samples and the chemical separations of $\mathrm{U}$ (and $\mathrm{Pu}$ ) were conducted either at the Enrico Fermi Institute at the Universicy of Chicago (UC) or at ANL. Only Auvergne was determined at both laboratories. Any possible contamination by enriched or depleted $U$ isotopes that may be present in the environment, equipment, or reagents could contribute to a difference between the results from these Auvergne: samples.

Procedures were developed for working with up to $300 \mathrm{~g}$ of volcanic rock with the option of combining three to four batches to process $1 \mathrm{~kg}$ of rock. Up to tens of $\mathrm{\mu g}$ of $\mathrm{U}$ can be recovered; thus, contamination related to environmental factors is reduced. In some experiments procedural blanks were run in parallel with the rock samples in order to further set limits on potential environmental and reagent contamination of the samples.

Rock fragments ( $>1 \mathrm{~cm}$ size) were first ultrasonically cleaned with distilled $\mathrm{H}_{2} \mathrm{O}$ followed by alcohol and ether washes and air or oven drying. Samples were then pulverized in a shatter box with a hardened-steel grinding container which was initially cleaned and rinsed by crushing and discarding aliquants of the rock fragments. The chemical procedure for dissolution of the rock was similar to that used by Fried et al. (6). The powdered rock was dissolved in two stages. An initial $\mathrm{HCl}$ treatment dissolved primarily olivine and some minor minerals such as phosphates. The residue from the HCl treatment was digested with $\mathrm{HNO}_{3}$ and $\mathrm{HF}$. The $\mathrm{HCl}$ soluble fraction was evaporated and then 
also digested in $\mathrm{HNO}_{3}-\mathrm{HF}$. All the samples, particularly the $\mathrm{HCl}$ insoluble fractions, had residues of $\mathrm{AlF}_{3}$ which were treated further (following the initial destruction of the silicates) by fuming several times with additional $\mathrm{HNO}_{3}$ and $\mathrm{HF}$ acids. $\mathrm{AlF}_{3}$ is soluble in excess $\mathrm{HF}$. Sufficient $\mathrm{HF}$ could not be added to dissolve all the $\mathrm{AlF}_{X}$, but we assume that digestion with $\mathrm{HF}$ caused release of any $U$ and that the hot $\mathrm{HNO}_{3}$ oxidized it to the fluoride-soluble $\mathrm{UO}_{2}{ }^{++}$state. Both fractions were evaporated to fumes of $\mathrm{HNO}_{3}$ to drive off $\mathrm{SiF}_{4}$ and excess $\mathrm{HF}$. These $\mathrm{HNO}_{3}$ solutions were sometimes combined for $U, T h$, and Pu chemistry; at other times, they were run separately. The latter procedure provided information on where $U$ is present in the rock and also made possible an additional assessment of possible environmental U contamination.

The succeeding chemical separation steps involved anion exchange columns, first with $8 \mathrm{MHNO}_{3}$ (nitrate column) to separate $\mathrm{Th}$ and $\mathrm{Pu}$ from $\mathrm{U}$ and $\mathrm{Fe}$, and then with $9 \mathrm{M} \mathrm{HCl}$ (chloride column) to adsorb $\mathrm{U}$ (and $\mathrm{Fe}$ ). Th and Pu were eluted from the nitrate column with conc. $\mathrm{HCl}$ and $0.1 \mathrm{M} \mathrm{HCl}$, respectively. $U$ and $\mathrm{Fe}$ were eluted from the chloride column with $0.1 \mathrm{M} \mathrm{HCl.} \mathrm{U}$ was subsequently ether extracted from an $\mathrm{NH}_{4} \mathrm{NO}_{3}$-saturated, $1 \mathrm{M} \mathrm{HNO}_{3}$ solution. After scrubbing with $1 \mathrm{M} \mathrm{HNO}_{3}-\mathrm{NH}_{4} \mathrm{NO}_{3}$ solution, the ether was allowed to evaporate over $\sim 5 \mathrm{ml}$ $0.1 \mathrm{M} \mathrm{HCl}$. Uranium recovered in the sample processing was determined from analysis of this $\mathrm{HCl}$ solution by laser fluorimetry with a SCINTREX Model UA3 Uranium Analyzer.

No tracers were used in the chemical separation procedures in order to avoid introducing this source of isotopic uncertainty. Furthermore, since it was impractical to monitor chemical yields during the chemistry, addition of tracers had no merit.

\subsection{Mass Spectrometry}

Uranium isotope ratios were measured with an automated, triple-filamentsource, thermal-ionization mass spectrometer (VG Ïsotopes, Mode1 54R). Corrections for isotopic fractionation during the mass spectrometric analysis were determined from multiple analyses of NBS uranium standard reference materials (SRM) from the series $\mathrm{U}-050$ through $\mathrm{U}-900 .{ }^{235} \mathrm{U} /{ }^{238} \mathrm{U}$ ratios measured for standard materials with this system are accurate to within $\pm 0.05 \%$ (one-sigma), relative, as demonstrated by calibration-verification data accumulated over several years.

For some of the measurements reported here, a portion of the solution containing the uranium sample prepared as described above was mixed with an isotope-dilution spike consisting of an accurately known quantity (nominally 10 $\mu \mathrm{g}$ ) of NBS SRM 995, which is a ${ }^{233} \mathrm{U}$ spike-assay and isotopic standard with a $233_{U}$ enrichment greater than $99.9 \%$. Each spike/sample mixture was evaporated to dryness several times from concentrated, NBS-distilled nitric acid to ensure complete isotopic equilibration, and the resultant residue was dissolved in $5 \%$ 
NBS nitric acid for loading on the mass spectrometer filament. From isotope ratios measured for the spiked sample and the known isotopic composition of the spike material, both the concentration and isotopy of the uranium in the sample aliquot were calculated.

In analyzing the first few samples in this series, we found that the sample solutions contained substantial amounts of extraneous salts (i.e., not uranyl nitrate), which adversely affected sample behavior during the mass spectrometric analysis, particularly for samples having a low uranium concentration and consequently requiring that a relatively large volume of solution be loaded on the filament. Under the hypothesis that these salts arose from aluminum or ammonium species that followed the uranium through earlier separations, an additional ion-exchange purification was performed on the spiked samples in the mass spectrometry laboratory. The uranium was absorbed on pre-washed Dowex AG1 anion exchange resin from $12 \mathrm{M}$ Ultrex $\mathrm{HCl}$ and eluted with $0.1 \mathrm{M}$ Ultrex $\mathrm{HCl}$. This treatment succeeded in eliminating the extraneous salts and dramatically Improved the stability of ion beams obtalned during the isotope ratio measurements.

A second portion of one sample solution (ANL-3, see Table) was analyzed with a different mass spectrometer (NBS Design, Teledyne Isotopes) and analysis procedure to verify the high enrichment of ${ }^{235} \mathrm{U}$ that was observed during analysis of the spiked aliquot prepared in the above manner. For this second aliquot, a portion of the unspiked sample solution was mixed on the mass spectrometer filament with a $233 \mathrm{U} /{ }^{236} \mathrm{U}$ internal standard spike that had previously been calibrated with NBS U-500 isotopic standard. The analysis procedure, described by Callis (1982), uses the measured ${ }^{233} \mathrm{U} /{ }^{236} \mathrm{U}$ ratio to determine a fractionation correction in real time during the run, and applies this correction to the $235_{\mathrm{U}} / 238_{\mathrm{U}}$ ratio measured for the unknown sample. In this way, the technique permits intercomparison of ${ }^{235} \mathrm{U} /{ }^{238} \mathrm{U}$ isotope ratios at the natural abundance level with very high prectsion. The result obtained in this way agreed well with the alternative measurement on the sample, demonstrating that the uranium in the sample solution was indeed enriched at the level indicated oy the first analysis.

For two sets of samples (ANL-7 and UC-5), uranium in the HCL sample solution was purified by taking the HCL solution to dryness, redissolving the residue in $3 \mathrm{~N}$ Ultrex $\mathrm{HNO}_{3}$, and adsorbing the $\mathrm{U}$ on an extraction-chromatography column containing 40 at. \% diamylamylphosphonate on $\mathrm{XAO}-7$ ion-exchange resin

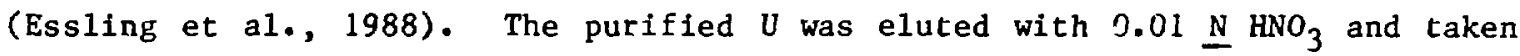
to dryness prior to redissolution for mass spectrometric analysis. These sample sets were analyzed by the ${ }^{234} \mathrm{U} /{ }^{236} \mathrm{U}$ internal standard procedure without addition to the ${ }^{233} \mathrm{U}$ assay spike. 
$235_{U} / 238_{U}$ in Volcanic Samples

\begin{tabular}{|c|c|c|c|}
\hline Sample* & $\begin{array}{c}235 / 238 \\
\text { (atom ratio) } \\
\end{array}$ & $\begin{array}{c}\delta 235 / 238 \% \\
(\text { sample/std - } 1) \\
\sigma= \pm 0.07 \% \\
\end{array}$ & $\begin{array}{c}\text { U recovered } \\
\mu \mathrm{g} \\
\end{array}$ \\
\hline \multicolumn{4}{|c|}{ Hat Creek basalt } \\
\hline UC-1S & 0.007371 & +1.62 & 5.78 \\
\hline UC-1R & 0.007272 & +0.26 & 10.14 \\
\hline$U C-2(S+R)$ & 0.007283 & +0.41 & 3.90 \\
\hline \multicolumn{4}{|c|}{ Auvergne volcanic bomb } \\
\hline ANL-3 $(S+R)$ & 0.007684 & +5.94 & 32.32 \\
\hline$U C-3 \quad(S+R)$ & 0.007301 & +0.66 & 5.21 \\
\hline \multicolumn{4}{|c|}{ Mt. St. Helens pumice } \\
\hline ANL-4 $(S+R)$ & 0.007267 & +0.19 & 4.52 \\
\hline \multicolumn{4}{|c|}{ Mauna Loa spatter } \\
\hline ANL-7S & 0.007284 & +0.43 & 0.41 \\
\hline ANL-7R & 0.007268 & +0.21 & 2.8 \\
\hline \multicolumn{4}{|l|}{ Kilauea 2565} \\
\hline$v C-5 S$ & 0.007249 & -0.06 & 0.34 \\
\hline$U C-5 R$ & 0.007257 & +0.06 & 5.7 \\
\hline \multicolumn{4}{|l|}{ Reagent blanks } \\
\hline UC-3 & (mass spect.) & & $<0.0075$ \\
\hline ANL-3 & (fluorescence) & & $<1$ \\
\hline \multicolumn{4}{|l|}{ Uranium } \\
\hline
\end{tabular}

*Chemical separation at Fermi Institute, University of Chicago = UC; at Argonne National Laboratory $=$ ANL. $S=\mathrm{HCl}$ soluble fraction; $\mathrm{R}=\mathrm{HCl}$ insoluble residue. 


\subsection{RESULTS}

The Table lists the results. The data we have acquired are not in conflict with the original observations (Fried et al., 1985) indicating a possible excess of ${ }^{235} U$ but cannot be accepted as proof as will be discussed. The $U$ isotopic ratios in all but one of the samples show an apparent enrichment of $235_{U}$ relative to normal uranium, with the enrichments ranging from $0.19 \%$ for the Mt. St. Helens pumice to $5.9 \%$ for one sample of the Auvergne volcanic bomb mater1al. In cases where the $\mathrm{HCl}$ acid soluble (S) and insoluble (R) fractions were measured separately (UC-1, UC-5, and ANL-7), the pattern appears to be higher excess $235_{U}$ in the $(S)$ samples. In interpreting the significance of these apparent enrichments, two important aspects must be considered. These are ( 1 ) potential contaminatior of the sample uranium with extraneous uranium containing a disproportionate abundance of ${ }^{235_{U}}$ and (2) potential errors in the mass spectrometric analysis.

A normal $235_{\mathrm{U} /}{ }^{238_{\mathrm{U}}}$ isotopic ratio was observed in only one case. Ironically, the sample Kilauea 2565, is the one in which Fried et al. (1985) found enriched $235_{\mathrm{U}}$. The relatively small enrichments observed with samples ANL-4 $(0.19 \%)$ and $U C-1 R(0.26 \%)$ are on the order of $3 \sigma$ uncertainties $(0.2 \%)$ in the mass spectrometric measurements when allowance is made for the difference between the analytical behavior of real-world samples and the ultra-pure standard materials used for calibrating the mass spectrometer, and might not be significant relative to potential mass spectrometric errors in these early measurements. However, ANL-7R (0.21\%) was measured later under more rigorous conditions and this number is significant. An internal standard procedure (Callis, 1982) that was used by Fried et al. (1985) was used for the ANL-7 and UC-5 samples.

We note that fried et al. (1985) reported that their sample of Mt. St. Helens ash (cf. ANL-4) was not enriched relative to normal uranium. However, we do not know whether the Fried et al. sample was pumice separated from other volcanic ejecta. We find a $235_{U}$ enrichment of $0.19 \%$ for Mt. St. Helens vesicular pumice sepnrated from dark "wall rock". However, this could be suspect. Sakuragi et al. (1983) reported that 235 enriched $U$ was found in rain samples falling about the time of the Mt. St. Helens eruption in May 1980. The anomalous $U$ was probably associated with the reentry of the Soviet satellite Cosmos 954 into the atmosphere in January 1978. Sakuragi et al. (1983) estimate a 20 month descent time of radioactive debris from the stratosphere to the tropopause.

The ${ }^{235} \mathrm{U}$ enrichments, $0.41 \% \rightarrow 5.9 \%$, measured for the other samples in this series are well outside the range of probable mass spectrometric errors, and clearly show an enhancement of the $235_{U}$ abundance in the uranium samples that were analyzed. It remains, however, to determine whether these enrichments are indigenous to the volcanic materials or resulted from ${ }^{235} \mathrm{U}$ contamination during 
the sample processing and preparation. As noted, dissolutions and chemical separations of the volcanic samples to isolate $U$ were conducted in parallel in two separate laboratories to help differentiate between indigenous enrichments and enrichments caused by contamination. If the ${ }^{235} \mathrm{U} /{ }^{238} \mathrm{U}$ ratio is a "constant of nature" then samples run at the two laboratories need not be the same rock to test for contaminant ${ }^{235} \mathrm{U}$.

Procedural blanks, run alongside the samples in each location, provide additional information which helps set limits to the potential for contamination from reagents, etc. used in processing the samples. Uranium in the reagent blank run with sample UC-3 was so low as not to be measurable with the (sensitive) isotope-dilution method we used to determine it; the blank corresponded to less than $0.2 \%$ of the uranium recovered from this sample. The blank run with sample ANL-3 was not examined as closely, but was shown to contain less than $1 \mathrm{~g} \mathrm{U}$, which corresponds to a blank smaller than $3 \%$ of the uranium obtained from the sample. Contamination of the samples by an amount of uranium corresponding to these upper limits in the blanks could, in principle, account for the enrichments that we found. However, the uranium in the blanks would have to be significantly enriched (at a level of at least $2 \%{ }^{235} \mathrm{U}$ compared to $0.7 \%$ for normal U). Although these arguments make contamination during preparation of the samples seem an unlikely source of the observed enrichments, we do see a difference between the Auvergne samples processed at UC and ANL. This difference could arise from differences in ${ }^{235_{U}}$ contamination as well as nonuniformity of the sample material.

We conclude with comments on specific samples listed in the Table. The $235 / 238_{U}$ isotopic ratios are not dependent on the amount of $\mathrm{U}$ recovered. The differences between samples of the same lava, ANL-3 and UC-3, for example, could be related to our failure to completely mix the material after it was pulverized. This process was carried out in a batch-wise fashion on "well mixed" sub-centimeter to centimeter-sized fragments. The UC-1S and UC-1R samples are soluble and residual fractions from $\mathrm{HCl}$ treatment of a $100 \mathrm{~g}$ sample in an initial UC experiment. In contrast to other Hat Creek samples, the amount of $U$ recovered from the residue (UC-1R) is large and has a nearer normal isotopic composition. Either isotopically different $U$ exists in the acid soluble and insoluble phases or the UC-IR sample reflects the effect of the extra chenical processing undertake. in an effort to determine whether any $U$ remained in the residue after $\mathrm{HF}-\mathrm{HNO}_{3}$ treatment to dissolve silicates. 


\subsection{CONCLUSIONS}

The results obtained thus far appear to support the earlier work of Fried et al. (1985). However, our Kilauea 2565 sample has isotoplcally normal $U$. The Mauna Loa spatter enrichments of $0.21 \%$ for the $\mathrm{HCl}$ insoluble residue (R) and $0.43 \%$ for the soluble fraction may be particularly important since spatters may have had the least exposure to enviromental $U$ present in meteoric and hydrothermal waters and crustal rocks. As is the case for all samples, laboratory environmental effects cannot be completely ruled out.

The relative ${ }^{235} \mathrm{U}$ enrichments of $0.2 \%$ are not inconsistent with the $0.18 \%$ relative enrichment reported by Fried et al. However, confirmation of the results must await acquisition of still more data and clarification of the source(s), if not intrinsic, of the isotopic variations observed. Other trace element isotopic measurements have raised questions regarding the mixing, hence homogeneity, of the mantle of the earth over geologic time. These U data, if confirmed, will be pertinent.

\subsection{AGRHONLEDGENTS}

The work reported here would not have been possible without the support and assistance of Karoline Wielgoz of the Enrico Fermi Institute, University of Chicago. Special thanks are extended to Edward 01sen, Field Museum of Natural History, Chicago, who provided the Kilauea sample and Auvergne volcanic bomb material. We also thank A. T. Anderson, Jr., University of Chicago, for the Hat Creek basalt sample, D. Swanson, USGS, for Mt. St. Helens volcanic ash and D. Finnegan, LASL, for the Mauna Loa spatter glass. The research was supported by the U. S. Department of Energy, Office of Basic Energy Sciences, Division of Engineering, Mathematical and Geosciences, under Contract W-31-109-Eng-38. 


\subsection{BIBLIOGRAPHY}

Anderson, Jr., A. T. and Gottfried P. (1972) Hat Creek Basalt, California: similarity to continental and oceanic-type basalts. EOS $\underline{53}, 547$.

Arden J. W. (1977) Isotopic composition of uranium in chondritic meteorites. Nature $269,788-9$.

Begemann F. (1980) Isotopic anomalies in meteorites. Reports on Progress in Physics 43, 1309-1356.

Callis E. L. (1982) Analytical Chemistry in Nuclear Technology, Proceedings of the 25th Conference on Analytical Chemistry in Energy Technology, W. S. Lyon, ed., Ann Arbor Science, Ann Arbor, MI, pp. 115-123.

Chen J. H. and Tilton G. R. (1979) Preliminary studies of uranium isotopic composition in chondritic meteorites. Lunar Planet. Sci. X, 192-4.

Chen J. H. and Wasserburg G. J. (1981) Isotopic composition of uranium and lead in Allende inclusions and meteorite phosphates. Earth Planet. Sci. Lett. 52, $1-15$.

Chen J. H. (1987) $\mathrm{U}, \mathrm{Th}$, and $\mathrm{Pb}$ isotopes in hot springs on the Juan de Fuca ridge. J. Geophys. Res. 92, B11, 11411-15.

Cowan G. W. and Adler H. H. (1976) The variability of the natural abundance of ${ }^{235} \mathrm{U}$. Geochim. Cosmochim. Acta 40, 1487-90.

Essling A. M., Graczyk D. G., and Horwitz E. P. (1988) Isolation and purification of uraniur from environmental materials for mass spectrometric analysis. 34th Annual Conference on Bioassay, Analytical, and Environmental Radiochemistry, Las Vegas, NV, October 17-21.

Fried S., Friedman A. M., Callis E., Schreiner F., Hines J., Orlandini K., Nelson D., and 01 sen E. (1985) Enrichment of ${ }^{235} \mathrm{U}$ and the concentration of ${ }^{239} \mathrm{Pu}$ in volcanic samples. Nature $313,301-303$.

Goel P. S. and Thakur A. N. (1987) Isotopically anomalous $\mathrm{Hg}$ in meteorites. Meteoritics (50th Annual Meeting, July 1987) 22, (4), 389-390.

Goel P. S. (1987) Variable ${ }^{190} \mathrm{Os} /{ }^{184} \mathrm{Os}$ ratio in acid residues of iron meteorites. Proc. Indian Acad. Sci. (Earth Planet. Sci.) 96, 81-102.

Grimanis A. P. and Pertessis-Keis M. (1987) Simultaneous determiration of mercury and selentum in biological materials by radiochemical neutron activation analysis. J. Radioanal. Nucl. Chem. 113, 445-451.

Jovanovic S. and Reed, Jr. G. W. (1976) $196 \mathrm{Hg}$ and $202 \mathrm{Hg}$ isotopic ratios in chondrites: revisited. Earth Planet. Sci. Lett. 31, 95-100.

Jovanovic S. and Reed, Jr. G. W. (1976) Interrelations among isotopically anomalous mercury fractions from meteorites and possible cosmological inferences. Science 193, 888-891.

Jovanovic S. and Reed, Jr. G. W. (1977) Preliminary results on isotopic measurements on trace elements in lunar breccias. Lunar Science VIII, pp. 519-521. Lunar Science Inst, Houston, TX. 
Jovanovic S. and Reed, Jr. G. W. (1977) Hg and Os isotopic variations in lunar breccias. Trans. Am. Geophys. Union 58 (6), 431.

Jovanovic S. and Reed, Jr. G. W. (1987) Isotopically anomalous $\mathrm{Hg}$ in Antarctic meteorites. Meteoritics (50th Annual Meeting, July 1987) 22, (4), 424-425.

Jovanovic S. and Reed, Jr. G. W. (1987) Isotopically anomalous $19 \mathrm{~h}_{\mathrm{Hg}}$ and ${ }^{202} \mathrm{Hg}$ in Antarctic achondrites. Geophys. Res. Lett. 14, (11), 1127-1130.

Luguair G. W., Marti K., and Scheinin N. B. (1978) Incomplete mixing of products from $\mathrm{K}-, \mathrm{P}-$, and S-process nucleosynthesis: Sm-Nd systematics in Allende Inclusion EK 1-04-1. Lunar and Planet. Sci. IX, 672-674.

Nier A. O. and Schlutter D. J. (1987) Mass spectrometric study of the mercury isotopes in the Allende meteorite: A preliminary report. Proc. 17th Lunar and Planet. Sci. Conf., J. Geophys. Res. 92, B4, E124-

Reed G. W., Kigoshi K., and Turkevich A. (1960) Determinations of concentrations of heavy elements in meteorites by activation analysis. Geochim. Cosmochim. Acta 20, 122-140.

Reed G. W. and Jovanovic S. (1969) ${ }^{196} \mathrm{Hg}$ and ${ }^{202} \mathrm{Hg}$ isotopic ratios in chondrites. J. Inorg. Nucl. Chem. 31, 3783-3788.

Sakuragi Y., Meason J. I., and Kuroda P. K. (1983) Uraniun and plutonium isotopes in the atmosphere. J. Geophys. Res. 88, 3.718-3724.

Takahashi H., Higuchi H., Gros J., Morgan J. W., and Anders E. (1976) Allende meteorite: isotopically anomalous xenon is accompanied by normal osmium. Proc. Nat1. Acad. Sci. USA 73, 4253-4255.

Tatsumoto M. and Shimamura T. $(1979)$ Evidence for live ${ }^{247} \mathrm{Cm}$ in the early solar system. Meteoritics $14,543-4$.

Tatsumoto M. and Shimamura T. (1980) Evidence for live ${ }^{247} \mathrm{Cm}$ in the early solar system. Nature 286, 108-122.

von Helden J. and Begemann F. (1976) On anomalous $\mathrm{Hg}$ in meteorites. Meteoritics 11,297 . 
Distribution for ANL-89/9

\section{Interna1:}

F. A. Cafasso

F. Y. Fradin

D. G. Graczyk (3)

D. W. Green

G. W. Reed, Jr. (6)

C. M. Stevens
L. M. Stock

ANL Patent Dept.

ANL Contract File

ANL Libraries

TIS Files ( 3 )

\section{Exierna1:}

DOE-OSTI, for distribution per (UC-401) (62)

Manager, Chicago Operations Office, DOE

G. A. Kohlstad, DOE, Washington, D.C.

J. S. Coleman, DOE, Washington, D.C.

D. C. Hoffman, University of California, Berkeley

G. J. Wasserburg, California Institute of Technology

J. H. Chen, California Institute of Technology

M. Tatsumoto, USGS, Denver, Colorado

G. R. Tilton, University of California, Santa Barbara

A. O. Nier, University of Minnesota

G. W. Cowan, Los Alamos Scientific Laboratory

D. L. Finnegan, Los Alamos Scientific Laboratory

A. L. Turkevich, University of Chicago

P. Goel, Indian Institute of Technology, Kanpur, India

F. Begemann, Max-Planck Institute, Mainz, West Germany

A. T. Anderson, University of Chicago

D. A. Swanson, USGS, Vancouver, Washington

E. J. Olsen, Field Museum of Natural History, Chicago 